\title{
Academics' perceptions of what it means to be an academic
}

Rosewell, K. ${ }^{\mathrm{a} *}$ and Ashwin, P. ${ }^{\mathrm{b}}$

${ }^{a}$ Department of Educational Research, Lancaster University, Lancaster, UK;

${ }^{b}$ Department of Educational Research, Lancaster University, Lancaster, UK

Kayleigh Rosewell, Department of Educational Research, Lancaster University, County South, Lancaster, LA1 4YD, UK, k.rosewell2@lancaster.ac.uk* 


\title{
Academics' perceptions of what it means to be an academic
}

\author{
Despite the wealth of literature on academic work, roles and identities, the \\ meaning of being an academic often does not go beyond such predefined and \\ separate roles of teacher, researcher, academic, professional and manager. \\ Consequently, our understanding of academic work is limited. This article \\ explores the holistic meaning of being an academic and considers how this relates \\ to gender. Based on interviews with 35 academics from a single United Kingdom \\ (UK) institution, we argue that what it means to be an academic, goes beyond \\ these pre-defined and separate roles; and that other aspects, such as academic \\ freedom, intellectual stimulation, and a sense of a calling play different roles in \\ different constructions of being an academic. Gender is also found to be an \\ important factor in the different ways of defining academic work. These findings \\ have implications for our understanding of career trajectories of male and female \\ academics.
}

Keywords: Higher Education; academic roles; academic work; academic identity; career perception; gender

\section{Introduction}

Despite the wealth of literature on academic work, roles and identities, the meaning of being an academic tends to be associated with, to varying degrees, autonomy and freedom, intellectual stimulation, teaching and research, and ideas around making a difference, and a sense of calling (Henkel 2000; Churchman 2006; Barnett and Napoli 2008; Fanghanel 2012; Boyd and Smith 2016). Previous studies have indicated that the latter has greater significance in the lives of early career academics (Churchman and King 2009; Hakala 2009). The variation in academics' roles has been described most notably in terms of the extent to which they identify with either being a researcher (Henkel 2000; Jawitz 2007; Archer 2008b; Kolsaker 2008; Ylijoki 2013), a teacher (Kreber 2010; Skelton 2012; Van Lankveld et al. 2017), a researcher and teacher (Henkel 2000, 2004; Whitchurch 2008; Feather 2010), an academic (Henkel 2000; Clegg 2008), a professional, (Whitchurch 2008, 2013) or a manager (Winter 2009). These roles however, have tended to be presented as having single meanings which is a rather simplistic view and overlooks the wider variation in academics' roles. Consequently, other elements of academic work, such as freedom, intellectual stimulation and ideas around making a 
difference, tend to be seen as the same and central to all academics' roles. This ignores the complexity and the different roles that these particular elements might play in the various notions of being an academic. A possible explanation for this could be that previous studies tend to focus on the atomistic experience of being an academic and the ways in which academics understand and prioritise pre-defined and separate elements of their work, thus re-producing this limited view. For example, in a study on policy change and academic identities, in 7 disciplines in 11 higher education institutions (HEIs) in England, Henkel (2000) discussed a view of teaching and research within a more holistic framework but gave very little detail about the meaning of this. Similarly, Clegg's (2008) study on academic identities, which was based on interviews with 13 academics in the UK, found that only one participant emphasised teaching as a priority, one prioritised research, while others prioritised their involvement with being an academic, an intellectual or practitioner. Although Clegg concluded that academic identity does not neatly fit into descriptions of teaching and research, and identified additional roles to these, all were presented as having single meanings.

We are aware that this may represent something of a basic picture of what it means to be an academic, but we have been struck by the frequency of this rather limited view across the existing literature on academic work and different kinds of contexts, such as institutional and disciplinary type (Becher and Trowler 2001; Trowler, Saunders, and Bamber 2012); career stage (Archer 2008a, 2008b; Churchman and King 2009; Hakala 2009; Fitzmaurice 2013; McKay and Monk 2017) and gender (Leathwood and Read 2009; Coate and Howson 2016). Although we acknowledge the importance of the impact of these different contexts and how they relate to experiences of academic work, gender inequality, in particular, remains an important issue for the higher education (HE) sector (see, e.g. Morley 2012, 2013, 2014; David 2016). Whilst this article does not explicitly focus on this, it does consider the relations between gender and what it means to be an academic, as a way to provide an additional perspective by drawing attention to the ways in which men and women construct the meaning of their academic roles. One of the explanations of gender inequality relates to academic time allocation; some literature has argued that women allocate more time to teaching and men to management and research, which are considered more important for an academic career (Harley 2003; Barrett and Barrett 2011; Morley2013; Coate and Howson 2016). In contrast, other studies have found no differences in time allocation to teaching and research (Asmar 1999; Carvalho 
and Santiago 2008; D 'Amico, Vermigli, and Canetto 2011; Santiago, Carvalho, and Vabø 2012). Studies on academic time allocation clearly offer mixed findings and, importantly, do not tell us why academics may (or may not) allocate their time differently to particular aspects of their work. An exploration of the holistic meaning of being an academic and how it relates to gender may provide an additional perspective and contribute to the research on gender and HE.

\section{Methods and Methodology}

In this article, we draw on the notion of Interpretative Phenomenological Analysis (IPA). IPA is a qualitative methodology rather than simply a means of analysing data and is concerned with the detailed exploration of personal lived experience (Smith, Flowers, and Larkin 2009; Smith 2011). IPA is underpinned by phenomenology, hermeneutics and idiography. The phenomenological lens of IPA is reflected in its commitment to examining a topic, as far as is possible, in its own terms (Eatough and Smith 2008). IPA recognises that this is an interpretative process, with the researcher trying to make sense of the participant who is trying to make sense of their experiences (Smith, Flowers, and Larkin, 2009). This connects IPA to hermeneutics, 'the theory of interpretation' (Smith, Flowers, and Larkin 2009, 3); and the 'hermeneutic circle' of moving back and forth between the part and the whole, to allow different ways of thinking about the data (Smith 2007, 5). Finally, a distinctive feature of IPA is its commitment to a detailed interpretative and idiographic account of each case in turn, prior to making more general claims.

IPA sampling is purposive, as the aim is to recruit participants for whom the research question is significant and can offer a meaningful perspective of the phenomenon of interest (Smith, Flowers, and Larkin 2009). The present sample includes 35 academics from a range of disciplines in a single research-intensive university in the UK. We use Biglan's (1973a, 1973b) typology to characterise the different disciplines involved and to protect participants' identity as their specific department is not named. Each participant has also been assigned a pseudonym. Participants varied according to age, gender, discipline, position and career stage.

Participants varied according to age, gender, discipline, position and career stage. Table 1 gives the demographic information for the sample. Most participants were aged 30-50 and were relatively evenly spread across early (5 years or less experience), middle (6-10 
years' experience) and late (11 or more years' experience) career stages, although academics from a mid-career stage were the smallest category. The sample consisted mainly of lecturers or senior lecturers, with only four readers (three males and one female) and two professors (all male). Therefore, one weakness of this study was that the sample included fewer people at the top of the academic career ladder and the other was that there was a gender imbalance. Further, it is important to recognise the limitations of basing any study in a single institution as the outcomes could be particular to it and may be different in other kinds of institutions (Trowler 1998). 
Table 1: Demographic variables

\begin{tabular}{|c|c|c|c|c|}
\hline Discipline & Pseudonym & Age & Position & $\begin{array}{l}\text { Career } \\
\text { stage }\end{array}$ \\
\hline \multirow{9}{*}{$\begin{array}{c}\text { Hard } \\
\text { applied }\end{array}$} & John & $40-50$ & Senior lecturer & Late \\
\hline & Andrew & $30-40$ & Professor & Late \\
\hline & Damon & $40-50$ & Senior lecturer & Late \\
\hline & Jack & $40-50$ & Lecturer & Late \\
\hline & Nathan & $30-40$ & Lecturer & Early \\
\hline & Sophie & $40-50$ & Senior lecturer & Middle \\
\hline & Miranda & $40-50$ & Senior lecturer & Late \\
\hline & Samantha & $40-50$ & Lecturer & Early \\
\hline & Jennifer & $40-50$ & Senior lecturer & Late \\
\hline \multirow[t]{8}{*}{ Hard pure } & Lewis & $50-60$ & Senior lecturer & Late \\
\hline & Jake & $40-50$ & Senior lecturer & Middle \\
\hline & Leon & $40-50$ & Reader & Middle \\
\hline & Rick & $40-50$ & Senior lecturer & Middle \\
\hline & Vicky & $40-50$ & Senior lecturer & Late \\
\hline & Kate & $40-50$ & Lecturer & Early \\
\hline & Zoe & $30-40$ & Lecturer & Early \\
\hline & Louise & $30-40$ & Lecturer & Early \\
\hline \multirow{8}{*}{$\begin{array}{c}\text { Soft } \\
\text { applied }\end{array}$} & Robert & $30-40$ & Lecturer & Early \\
\hline & Mark & $30-40$ & Lecturer & Middle \\
\hline & Max & $40-50$ & Lecturer & Early \\
\hline & Graham & $30-40$ & Lecturer & Early \\
\hline & Michelle & $30-40$ & Lecturer & Late \\
\hline & Hayley & $30-40$ & Lecturer & Early \\
\hline & Kirsty & $30-40$ & Lecturer & Early \\
\hline & Jade & $30-40$ & Senior lecturer & Late \\
\hline \multirow[t]{10}{*}{ Soft pure } & Michael & $40-50$ & Reader & Late \\
\hline & Richard & $50-60$ & Senior lecturer & Late \\
\hline & Dylan & $40-50$ & Professor & Late \\
\hline & Mathew & $50-60$ & Reader & Late \\
\hline & Jason & $30-40$ & Lecturer & Middle \\
\hline & Christopher & $30-40$ & Lecturer & Middle \\
\hline & Rebecca & $30-40$ & Lecturer & Early \\
\hline & Sandra & $40-50$ & Reader & Middle \\
\hline & Natalie & $40-50$ & Senior lecturer & Middle \\
\hline & Deborah & $40-50$ & Lecturer & Late \\
\hline
\end{tabular}


In line with IPA and the aims of this research, data were generated through semistructured interviews, as this method allows participants to offer rich, detailed and reflective accounts of their experience. The interviews focused on academics' perceptions of what it means to be an academic and the ways in which they experience and perform this role. Each interviewee was asked about their journey into an academic career, a typical working week, their likes and dislikes in their work, their career ambitions and views about the key elements of being an academic. With regard to data analysis, although IPA does not have a single method of analysis, "it can be characterised by a set of common processes: moving from the particular to the shared, and from the descriptive to the interpretative; and principles: a commitment to understanding the participant's point of view, and a focus on personal meaning-making' (Smith, Flowers, and Larkin 2009, 79). For the purpose of this research, we followed Smith, Flowers, and Larkin's (2009) six steps to IPA, which provide a clear set of thorough and accessible guidelines:

1. Reading and re-reading the transcripts

2. Initial noting

3. Developing emergent themes

4. Searching for connections across emergent themes

5. Moving to the next case and

6. Looking for patterns across cases

This first step involved immersion in the data, reading and re-reading the transcript, noting any initial or striking observations. The first reading also involved listening to the audio-recording, as this allowed the participant to become the focus of the analysis. The second step involved an examination of semantic content and language use, noting anything of further interest, to allow a set of descriptive and exploratory comments to be developed with a clear phenomenological focus that remained close to the participant's own words. The third stage involved a process of turning notes into themes that also remained close to the participant's own words. Step four relied on a process of abstraction for identifying patterns between emergent themes and developing a sense of a 'superordinate' theme (Smith, Flowers, and Larkin 2009, 96). This involved putting like with like, developing a name for that cluster and producing a table of super-ordinate themes. Step five involved moving to the next transcript and repeating the process. Once each 
transcript had been analysed and a set of super-ordinate themes had been created for each participant, step six focused on looking for patterns and developing a master table of themes that firmly reflects participants' own words.

In this article, we focus on validity rather than reliability because, as already discussed, the findings may not be replicated at different types of HEIs and/or with a different sample. Kvale and Brinkmann (2009) argue that validity is widely seen as the extent to which a study is seen as investigating what it aimed to investigate, or the extent to which the research outcomes reflect the phenomenon being studied. We drew on Kvale and Brinkmann's (2009) notions of validity as quality of craftsmanship and communicative and pragmatic validity. In doing so, we focused on the extent to which our research findings corresponded to human experience of the phenomenon and how well they corresponded to the phenomenon as it existed in 'reality' (Åkerlind 2005).

In a context of multiple legitimate interpretations of the same data, our focus was not on a search for the 'right' interpretation, but for an interpretation that was defensible (Kvale and Brinkmann 2009). Communicative validity emerges through conversation between the research outcomes and the reader and various readers and discussants, where valid knowledge is constituted when the audience can see new relations and answer new questions and advance sensible discussion in the area (Kvale and Brinkmann 2009). Part of this approach to validity involves ensuring that the research methods and final interpretation are regarded as appropriate by the relevant research community accessed through research seminars, conference presentations and peer-reviewed journals. Finally, pragmatic validity refers to the extent to which the research outcomes are seen as useful and meaningful to their intended audience (Kvale and Brinkmann 2009). While the study was small and based within a single UK HEI, we believe we have provided a useful contribution to the research on academic work, roles and identities and how these relate to gender. 


\section{Findings}

Participants identified three central meanings of being an academic: as a teacher, as a researcher and as a general view of an academic, and there was variation in the meaning of the two latter roles.

\section{Being a Teacher}

Four participants viewed their academic role as being a teacher and an educator, showing students how to understand the subject and passing on their interest, enthusiasm and passion. Although these participants viewed their work as 'just a job', expressions of commitment, pride and passion were evident in their accounts and particularly for Deborah and Jennifer, expressions of love for their work were also evident.

\section{Being a Researcher}

Thirteen participants discussed how, for them, being an academic meant being a researcher. Although they had a shared understanding of research as the process of knowledge creation and transmission, when looking closely at their accounts, there appeared to be three different understandings of research: as a creative process, as a process of discovery, or as professional recognition.

\section{Research as a creative process}

Four participants viewed being a researcher as a creative process which involved the intellectual stimulation, excitement and challenge of being a researcher. This creativity could be experienced across a variety of activities including thinking, reading, writing, conversations and empirical work, and across various settings of academic work. As Robert explained, 'It's like a huge puzzle, and the pieces come from the different types of work I do and from my research, teaching, conferences, all sorts'. Further, for these participants, being an academic tended to be selffocused, as their roles were centred on having an exciting and challenging career, following their personal interest and satisfying a creative urge.

For the two women in this group, the creative process was discussed as essential to their sense of self as a researcher. Jade explained: 'Research is a really big part of my identity, I'm quite a creative sort of person so it's just who I am'. Similarly, 
Sandra said 'I have to be doing some [research] a lot of the time otherwise I'm not very happy, I've always been into writing and stuff so it's a continuation of who I am'. These comments give a sense that being a researcher and creative is compulsive and something that is fundamental to their sense of self. Interestingly, this view of research was not present in the accounts of the male academics; Michael and Robert viewed being an academic as 'just a job'.

\section{Research as a process of discovery}

Three participants defined being a researcher as a process of discovery, which gives the opportunity to explore the unknown and ask questions that need answering, particularly those aimed at addressing a real-life problem:

It's about doing excellent research but also research that has a social impact, I don't want to sound overly altruistic or whatever, but I think for me it's very important that what I do is, not only write papers, people cite your work and say, 'Oh that's really great work', there should actually be some sort of something else, I don't mean two months down the line, it could be ten years down the line or whatever, you want to see something that will ultimately lead to a benefit for society. So, I guess the publications are important because you need to publish it in order to do that, but the publication is not the driving force. (Andrew)

This was representative of the three participants' views that the central meaning of being a researcher is to produce quality research that addresses a real-life problem and not primarily for their standing within the field or for personal recognition. It is also important to mention that Hayley and Rebecca viewed being an academic as 'central to who I am', whereas for Andrew it was not constructed in this way.

\section{Research as professional recognition}

For the other six participants, the purpose of being a researcher was for professional recognition, as Jack explained: 'I want to be well-known for what I do in research, that's the key thing for me; being invited to a conference because you're the best person on that subject, an expert'. This quotation was representative of participants' views in this group and highlights the importance placed on being well-known and viewed as an expert. These participants were primarily driven by the desire to obtain 
funding for and publishing research, and career advancement, which were perceived as directly related to professional recognition. Interestingly, Jack, Max, Mark and Jake stated that being an academic is 'just a job' that provided a salary and recognition, whereas Samantha perceived it as being part of her individual sense of self.

This view of what it means to be an academic appeared particularly focused on professional recognition and standing within the field, rather than on providing a contribution for the sake of the field. However, the drive for professional recognition seemed to cause a great deal of pressure, frustration and anxiety. For instance, Samantha discussed the experience of being faced with 'competition from other researchers in the country and around the world' as a significant cause of anxiety and pressure. Will also highlighted the challenge 'to stay research active' and the difficulty of obtaining research grants and perceived this aspect of the job as 'a bit demoralising' if unsuccessful.

\section{A general view of being an academic}

Eighteen participants had a more general view of being an academic. While teaching and research were perceived as essential, this view tended to be wider and all-encompassing. Participants in this group had different notions about what it means to be an academic, which could broadly be categorised as: being either selffocused or concerned with providing a contribution.

\section{Being an academic as self-focused}

Twelve participants viewed being an academic as self-focused, although interviewees expressed slightly different meanings. Six viewed being an academic as an enjoyable job that they had always wanted to do. Teaching and research were described as the driving force into their academic career but they loved all aspects of being an academic and could not imagine doing anything else. For other participants, what it means to be an academic was not defined in terms of activities. For example, Damon defined it as having 'the freedom to pursue your own work directions' and Christopher perceived his role as 'a neutral kind of space to reflect on what's going on in the world'. Leon, Mathew, Jason and Richard viewed it in various ways, as exciting, satisfying, rewarding, meaningful and worthwhile. It is 
clear from the above responses that these all are self-focused views of what it means to be an academic. While these notions represent slightly different meanings, they tend to focus on all aspects of being an academic and are not always confined to a particular activity, such as teaching and/or research.

Some participants in this group expressed mixed views about whether they perceived academic work as a job or as something more. Louise, Miranda and Dylan viewed it as more than simply a job and as 'part of' their individual sense of self. In contrast, Leon, Richard, Jason and Christopher saw it as 'just a job'. Interestingly, Rick, Mathew and Damon viewed it as an 'important part' of their sense of self yet simultaneously described it as also 'just a job'.

\section{Being an academic as providing a contribution}

For the other six participants, being an academic involves providing a contribution. Sophie explained that it 'is about providing society with the best trained people and doing something that ultimately benefits the lives of students as well as society'. Likewise, Nathan said 'an academic should be a person who is able to draw out the strengths and weaknesses in students and fill the gaps [as well as] addressing reallife problems through our work'. These responses emphasise how these participants see the importance of providing a contribution to the lives of students, to support them in their professional, intellectual and personal growth; as well as to society. Although participants in this group valued academic freedom, intellectual stimulation, and the sense of happiness, reward and fulfilment from being an academic, providing a contribution for the sake of society and students was emphasised as essential to their role.

Again, most participants in this group also expressed views about whether they perceived being an academic as just a job or as something more. Sophie and Nathan described it as 'just a job' whereas Kirsty and Natalie expressed the view that it was 'more than a job'. It is also important to mention that for Michelle being an academic was also defined as her purpose in life, she explained 'it's something that I do because I have to do this, it's what I'm built for, I genuinely feel that this is my role in this world and that's what I'm here to do'. Although other participants in 
this study expressed the view that being an academic was part of their personal identity, Michelle's view was all encompassing.

\section{The relations between what it means to be an academic and gender}

Gender appeared to have little influence on the participants' three main constructions of being an academic, but had a greater impact on some individual interpretations of what it meant to be a researcher and a general view of being an academic. Table 2 details the number of men and women according to these different meanings of being an academic.

Table 2: Central meanings of being an academic and gender

\begin{tabular}{l|l|l}
\hline \multicolumn{1}{c|}{ Being an academic } & Men & Women \\
\hline Being a teacher & 2 & 2 \\
\hline Being a researcher as a creative process & 2 & 2 \\
\hline Being a researcher as a process of discovery & 1 & 2 \\
\hline Being a researcher as professional recognition & 4 & 2 \\
\hline A general view of being an academic as self-focused & 8 & 4 \\
\hline $\begin{array}{l}\text { A general view of being an academic as providing a } \\
\text { contribution }\end{array}$ & 2 & 4 \\
\hline
\end{tabular}

Table 2 shows that the women academics were relatively evenly spread within each meaning, whereas the men tended define being an academic as being a researcher for the purpose of professional recognition and being an academic more generally as self-focused. There also appear to be gender differences when looking at those roles that were self-focused ( 8 women and 14 men) and those that focused on providing a contribution ( 6 women and 3 men). Furthermore, although participants were not asked directly whether they viewed being an academic as just a job or as something more, most expressed one of these views. Whilst all participants viewed their academic work as important, the women in this study were more likely to perceive it as more than a job and as part of their individual sense of self ( 10 females and 1 male), whereas the men were more likely to perceive it as just a job (13 males and 3 females).

\section{Discussion}

This article provides a more detailed and varied picture of what it means to be an academic. It highlights multiple rather than single meanings, and several dimensions, such as whether academics are self-focused or concerned with 
providing a contribution; whether being an academic is perceived as just a job or as something more; and whether particular aspects of academic work are perceived as central or as desirable. These findings have not been found in previous studies on academic work, roles and identities (Henkel 2000; Barnett and Napoli 2008; Fanghanel 2012; Boyd and Smith 2016). Moreover, this article shows greater variation in academics' roles that go beyond simply being a researcher (Henkel 2000; Jawitz 2007; Archer 2008b; Kolsaker 2008; Ylijoki 2013), a teacher (Kreber 2010; Skelton 2012; Van Lankveld et al. 2017), a researcher and teacher (Henkel 2000, 2004; Whitchurch 2008; Feather 2010), an academic (Henkel 2000; Clegg 2008), a professional (Whitchurch 2008, 2013), or a manager (Winter 2009).

The current findings also suggest that particular elements of academic work play different roles in different views of what it means to be an academic. We found that the idea of making a difference (Churchman 2006) was considered essential for being a researcher as a process of discovery and a general view of being an academic as providing a contribution, but it was not present at all in the accounts of being a researcher as a creative process or for professional recognition or a general view of being an academic as self-focused. The intellectual stimulation, excitement and challenge of academic work was seen as: central for being a researcher as a creative process and in some accounts of a general view of being an academic as self-focused; positive features in the accounts of a general view of being an academic as providing a contribution; but not mentioned in the accounts of being an academic as a teacher or as a researcher for professional recognition or as a process of discovery. Therefore, the idea that all academics care about the intellectual nature of academic work and in the same way for instance, conceals the different role that this might play in different notions of being an academic. When focusing on the holistic rather than atomistic meaning of being an academic we can begin to distinguish between aspects of academic work that are perceived as positive and desirable, and aspects that are key to what it means to be an academic, which have not been found in existing literature on academic work. These findings are important as they provide a deeper understanding of academic work and the 
different meanings, priorities and motivations academics have towards their work and career trajectories.

An important finding in this article relates to the way in which male and female academics perceive the meaning of their roles. The male academics tend to be selffocused and view their work as just a job whereas the women tend to see their roles as more than a job, as a central part of themselves, and their work as providing a contribution. Previous studies have argued that this view of academic work as being a calling rather than just a job is more common among early career academics (Churchman and King 2009; Hakala 2009). However, we suggest that gender may also influence this view, which is important because if men tend to view their work as just a job and in a self-focused way, it is likely that they are able to approach career advancement differently for instance, and their career trajectories are likely to look different to those (women in this study) who tend not to hold these views. These findings partly contribute to and build on existing research in gender inequality (Leathwood and Read 2009; Morley 2012, 2013, 2014; David 2016) and time allocation and preferences towards teaching and research (Asmar 1999; Harley 2003; Carvalho and Santiago 2008; Barrett and Barrett 2011; D 'Amico, Vermigli, and Canetto 2011; Santiago, Carvalho, and Vabø 2012; Morley 2013; Coate and Howson 2016).

\section{Conclusion and Implications}

This study explored the holistic meaning of being an academic and has highlighted a wider and more varied picture of academic work that had not been seen in more atomistic approaches. There were three main views about what it means to be an academic: a teacher, a researcher or a general view of an academic. Being a researcher was understood as a creative process, a process of discovery or for professional recognition. A general notion of being an academic was not confined to a single aspect of academic work and encompassed the broader aspects of the role; and was either concerned with providing a contribution of was self-focused. Within each meaning, there were several dimensions, such as whether being an academic meant being self-focused or concerned with providing a contribution; whether academics perceived their work as just a job or as something more; and whether certain aspects of academic work were perceived as central or desirable or 
not discussed at all. Interestingly, there was no variation in views about what it means to be an academic as a teacher. This could be due to the small number of participants that indicated a teaching-focused view of their role, and the researchintensive focus of the institution. Greater variation may have been shown with a larger sample and with different types of institutions.

These findings contribute to the existing literature on academic work, roles and identities by encouraging us to move beyond the view that the associated roles of being an academic as a teacher, researcher, academic, professional or manager has the same meaning for all academics. Similarly, it is important to recognise that academic freedom, intellectual stimulation, providing a contribution or making a difference, and a sense of calling are not central to all academics' roles in the same way. This has important implications for academic careers and progression because some academics, whose main goal is professional recognition, are likely to be more focused on career advancement compared to those who attach other meanings to their role, such as having an exciting career or making a contribution.

As universities strive to widen participation and retention of academic staff as well as students from different backgrounds, it would seem reasonable to highlight the importance for universities to move away from a 'one-size-fits-all' approach to being an academic, and measures of success, such as the importance placed on research publications; and the potential exclusion of other criteria, such as success in teaching and providing a contribution to the lives of students and/or to society, and other meanings of being an academic that do not centre on research.

Although this study did not set out to investigate gender inequality in HE, the findings provide an important contribution to, and have implications for this area of work, and suggest that gender impacts on academics' views about what it means to be an academic. It is likely that these views impact on the different ways that men and women perceive and approach their academic careers and as such, this article enhances our understanding.

It is important to acknowledge the limitations of this research. This study was based on a single UK research-intensive institution and the findings may be specific to the 
institution and its context. This may have contributed to the high number of staff that viewed their role as research focused, and the variation in the meaning of that role to different academics, in comparison to the small number of those with a teaching-focused role which was not viewed in diverse ways. These findings may have been different if the research had been conducted at a teaching or vocational institution. The sample was also under-represented by academics at the top of the career ladder, and the few of those participants were male. An area for future research would be to widen the sample in terms of institutional and disciplinary focus and diversity in terms of academics, particularly those at the top of the career ladder. With a larger and more diverse sample, future research could explore whether the views expressed about what it means to be an academic are shared; and additional meanings and relations between particular demographic variables could be potentially uncovered.

\section{References}

Åkerlind, Gerlese S. 2005. "Postdoctoral Researchers: Roles, Functions and Career Prospects." Higher Education Research and Development 24 (1): 21-40.

Archer, Louise.2008a. "The New Neoliberal Subjects? Younger Academics"

Constructions of Professional Identity." Journal of Education Policy 23 (3): 265-85.

Archer, Louise. 2008b. "Younger Academics" Constructions of "Authenticity', "Success" and Professional Identity." Studies in Higher Education 33 (4): 385403.

Asmar, Christine. 1999. "Is There a Gendered Agenda in Academia? The Research Experience of Female and Male PhD Graduates in Australian Universities." Higher Education 38 (3): 255-73.

Barnett, Ronald, and Robert DiNapoli, eds. 2008. Changing Identities in Higher Education: Voicing Perspectives. London: Routledge. Barrett, Lucinda, and Peter Barrett. 2011. "Women and Academic Workloads: Career Slow Lane or Cul-de-Sac?" Higher Education 61 (2): 141-55.

Becher, Tony, and Paul Trowler. 2001. Academic Tribes and Territories: Intellectual Enquiry and the Cultures of Disciplines. 2nd ed. Buckingham: Society for Research into Higher and Open University Press. 
Biglan, Anthony. 1973a. "The Characteristics of Subject Matter in Different Academic Areas." Journal of Applied Psychology 57 (3): 195-203.

Biglan, Anthony. 1973b. "Relationships Between Subject Matter Characteristics and the Structure and Output of University Departments." Journal of Applied Psychology 57 (3): 204-13.

Boyd, Pete, and Carline Smith. 2016. "The Contemporary Academic: Orientation

Towards Research Work and Researcher Identity of Higher Education Lecturers in the Health Professions." Studies in Higher Education 41 (4): 678-95.

Carvalho, Teresa, and Rui Santiago. 2008. "Gender Differences on Research: The Perceptions and Use of Academic Time." Tertiary Education and Management 14 (4): 317-30.

Churchman, Deborah. 2006. "Institutional Commitments, Individual Compromises: Identity-Related Responses to Compromise in an Australian University.” Journal of Higher Education Policy and Management 28 (1): 3-15.

Churchman, Deborah, and Sharron King. 2009. "Academic Practice in Transition: Hidden Stories of Academic Identities." Teaching in Higher Education 14 (5): $507-16$.

Clegg, Sue. 2008. “Academic Identities Under Threat?” British Educational Research Journal 34 (3): 329-45.

Coate, Kelly, and Camille Kandiko Howson. 2016. "Indicators of Esteem: Gender and Prestige in Academic Work." British Journal of Sociology of Education 37 (4): $567-85$.

D’Amico, Rita, Patrizia Vermigli, and Siliva Sara Canetto. 2011. "Publication Productivity and Career Advancement by Female and Male Psychology Faculty: The Case of Italy.” Journal of Diversity in Higher Education 4 (3): 175-84.

David, M. E. 2016. "Women and Gender Inequality in Higher Education?” In The Changing Role of Women in Higher Education: Academic and Leadership Issues, edited by Heather Eggins, 209-25. Springer International Publishing. Eatough, Virginia, and Jonathan Smith. 2006. “'I Was Like a Wild Wild Person': Understanding Feelings of Anger Using Interpretative Phenomenological Analysis.” British Journal of Psychology 97 (4): 483-98.

Fanghanel, Jöelle. 2012. Being an Academic. London: Routledge.

Feather, Denis.2010. “A Whisper of Academic Identity: An HE in FE Perspective.” Research in Post-Compulsory Education 38 (4): 613-622. 
Fitzmaurice, Marian. 2013. "Constructing Professional Identity as a New Academic: A Moral Endeavour." Studies in Higher Education 38 (4): 613-22.

Hakala, Johanna.2009. "The Future of the Academic Calling? Junior Researchers in the Entrepreneurial University." Higher Education 57: 173-90.

Harley, Sandra. 2003. "Research Selectivity and Female Academics in UK Universities:

From Gentleman's Club and Barrack Yard to Smart Macho?” Gender and Education 15 (4): 377-92.

Henkel, Mary. 2000. Academic Identities and Policy Change in Higher Education.

London: Jessica Kingsley Publishers Ltd.

Henkel, Mary. 2004. "Teaching and Research: The Idea of a Nexus.” Higher Education Management and Policy 16 (2): 19-30.

Jawitz, Jeff. 2007. "New Academics Negotiating Communities of Practice: Learning to Swim with the Big Fish.” Teaching in Higher Education 12 (2): 185-97.

Kolsaker, Ailsa. 2008. “Academic Professionalism in the Managerialist Era: A Study of English Universities.” Studies in Higher Education 33 (5): 513-25.

Kreber, Carolin. 2010. "Academics" Teacher Identities, Authenticity and Pedagogy." Studies in Higher Education 35 (2): 171-94.

Kvale, Steinar, and Svend Brinkmann. 2009. Interviews Learning the Craft of

Qualitative Research Interviewing. 2nd ed. London: Sage.

Leathwood, Carole, and Barbara Read. 2009. Gender and the Changing Face of Higher Education: A Feminized Future? Berkshire: Society for Research into Higher Education and Open University Press.

McKay, Loraine, and Sue Monk. 2017. "Early Career Academics Learning the Game in Whackademia.” Higher Education Research and Development 36 (6): 1251-63. Morley, Louise. 2012. "Cycles of Domination of Top Roles by Men Must be Broken.” Times Higher Education, December 6.

Morley, Louise. 2013. "The Rules of the Game: Women and the Leaderist Turn in Higher Education." Gender and Education 25 (1): 116-31.

Morley, Louise. 2014. "Lost Leaders: Women in the Global Academy.” Higher Education Research and Development 33 (1): 114-28.

Santiago, Rui, Teresa Carvalho, and Agnete Vabø. 2012. "Personal Characteristics, Career Trajectories and Sense of Identity Among Male and Female Academics in Norway and Portugal.” In Effects of Higher Education Reforms: Change Dynamics, edited by Martina Vukasović, Peter Maassen, Monika Nerland, 
Rómulo Pinheiro, Bjørn Stensaker, and Agnete Vabø, 279-303. Rotterdam: Sense Publishers.

Skelton, Alan. 2012. "Teacher Identities in a Research-led Institution: in the Ascendancy or on the Retreat?" British Educational Research Journal 38 (1): 23-39.

Smith, Jonathan A. 2007. "Hermeneutics, Human Sciences and Health: Linking Theory and Practice." International Journal of Qualitative Studies on Health and WellBeing 2: 3-11.

Smith, Jonathan A. 2011. "Evaluating the Contribution of Interpretative Phenomenological Analysis.” Health Psychology Review 5 (1): 9-27.

Smith, Jonathan A., Paul Flowers, and Michael Larkin. 2009. Interpretative Phenomenological Analysis: Theory, Method and Research. London: Sage Publications.

Trowler, Paul. 1998. Academics Responding to Change: New Higher Education Frameworks and Academic Cultures. Buckingham: Open University Press. Trowler, Paul, Murray Saunders, and Veronica Bamber, eds. 2012. Tribes and Territories in the 21st Century: Rethinking the Significance of Disciplines in Higher Education. Abingdon: Routledge.

Van Lankveld, Thea, Judith Schoonenboom, Monique Volman, Gerda Croiset, and Jos Beishuizen. 2017. "Developing a Teacher Identity in the University Context: A Systematic Review of the Literature." Higher Education Research and Development 36 (2): 325-42.

Whitchurch, Celia. 2008. "Shifting Identities and Blurring Boundaries: The Emergence of Third Space Professionals in UK Higher Education.” Higher Education Quarterly 62 (4): 377-96.

Whitchurch, Celia. 2013. Reconstructing Identities in Higher Education: The Rise of Third Space Professionals. London: Routledge.

Winter, Richard. 2009. “Academic Manager or Managed Academic? Academic Identity Schisms in Higher Education.” Journal of Higher Education Policy and Management 31 (2): 121-31.

Ylijoki, Oili Helena. 2013. "Boundary-Work Between Work and Life in the High-Speed University." Studies in Higher Education 38 (2): 242-55. 
